\title{
Preliminary Study on the Effect of Sleepwear on Objective and Subjective Sleep Quality
}

\author{
Ha Young Lee, Mi hyun Lee, Jeong Eun Jeon, Kyung Hwa Lee, and Yu Jin Lee \\ Department of Psychiatry and Center for Sleep and Chronobiology, Seoul National University College of Medicine, \\ Seoul National University Hospital, Seoul, Korea
}

\begin{abstract}
Objective: This preliminary study examined whether sleepwear affected sleep parameters using nocturnal polysomnography (nPSG) and self-reported questionnaire in healthy adults. Methods: Fourteen participants were recruited (nine females and five males; mean age, $29.43 \pm 8.58$ years). nPSG was conducted for three consecutive nights, including the adaptation night, and self-reported questionnaires about sleepwear and sleep parameters were completed. On the second and third nights after the adaption night, participants were randomly assigned to a group wearing the DPV576 experimental sleepwear (ES) on the first night with the control sleepwear (CS) worn the following night, or a group wearing the two types of sleepwear in the reverse order. The objective and subjective sleep parameters for each night were compared using the paired t-test. Results: Objective sleep variables were not significantly different between the two types of sleepwear. However, total sleep time (TST) on nPSG tended to be higher when participants wore the ES than the CS ( $p=0.06$ ) in the results of nine who reported relatively high sleep quality (Pittsburgh Sleep Quality Index $<5$ ). When wearing the ES all participants reported more frequent dream $(p=0.03)$, and less discomfort caused by sleepwear while lying down and moving in bed (i.e., tossing and turning), than the CS ( $p=0.04)$. Conclusion: These results suggest that sleepwear type might affect objective sleep parameters (e.g., TST on nPSG) and be associated with changes in subjective sleep measures, such as the frequency of dreams and the discomfort caused by tossing and turning.
\end{abstract}

Keywords: Sleep quality; Functional sleepwear; Polysomnography

Received: May 12, 2020 Revised: May 19, 2020 Accepted: May 20, 2020

Corresponding author: Yu Jin Lee, MD, PhD, Department of Psychiatry and Center for Sleep and Chronobiology, Seoul National University College of Medicine, Seoul National University Hospital, 101 Daehak-ro, Jongno-gu, Seoul 03080, Korea.

Tel: 82-2-2072-2456, Fax: 82-2-744-7241,E-mail: ewpsyche@snu.ac.kr

(c) This is an Open Access article distributed under the terms of the Creative Commons Attribution Non-Commercial License (https://creativecommons.org/licenses/bync/4.0) which permits unrestricted non-commercial use, distribution, and reproduction in any medium, provided the original work is properly cited.

\section{INTRODUCTION}

Sleep plays an important role in human health. It has been demonstrated that insufficient sleep and poor sleep quality are associated with physical, physiological, and psychological impairments [1]. The sleep environment, including sleepwear, bedding, and the mattress, are considered factors conducive to better sleep quality [2-5].

Sleepwear improves the quality of sleep by preventing the body temperature from dropping sharply [2,6]. Previous studies have reported that sleepwear affects body temperature during sleep. One study showed that "body-pressing sleepwear" resulted in making the rise of skin temperature and the decline of rectal temperature less, which could affect circadian rhythm [7]. Researchers also found that among several materials (e.g., wool, cotton, and polyester) the insulating properties of wool sleepwear pro- moted sleep and improved sleep quality [8,9]. Sleepwear is not only used to preserve body temperature, but also to control it. One study reported that functional sleepwear with a cooling effect was effective for women with sleep disturbances [10].

DPV576 is a mixture of nanodiamond and nanoplatinum solutions that improves immunity and reduces physical fatigue [11]. In vitro studies with DPV576 showed supportive helpful results related to cancer treatment [12-15]. For example, a study observed that exposure to DPV576 resulted in decreased cell stiffness of metastatic murine breast cancer cells compared to control cells [13]. Another showed that DPV576 mixture activated human dendritic cells and dendritic cells-driven CD4 naive T-cell proliferation in vitro, which implies that the material might help immunity to cancer [15]. Studies on athletes suggested that DPV576 functional sleepwear might help recovery from physical and psychological stress after intensive training [16-18]. The 
stress-reducing effects on keratinocytes expected to be provided by DPV576 might be associated with circadian rhythms [19].

Few studies have explored whether there are differences in objective and subjective sleep parameters between functional and standard sleepwear. In this study, an experiment was conducted comparing DPV576 functional sleepwear (experimental sleepwear; ES) and similarly manufactured normal sleepwear (control sleepwear; CS). It was hypothesized that the type of sleepwear would influence objective and subjective sleep parameters.

\section{METHODS}

\section{Participants}

Nine females and five males (mean age, $29.43 \pm 8.58$ years) were recruited through an advertisement. The exclusion criteria were as follows: 1) females who were pregnant/nursing; 2) a history of serious medical problems; 3 ) currently taking medications that act on the nervous system, including sleeping pills; 4) DSM-5based psychiatric diagnosis [20] within the last 3 months; 5) symptoms of a sleep disorder, such as insomnia, snoring, apnea, daytime sleepiness, or restlessness in the legs before bedtime; and 6) shift worker. This study was approved by the Institutional Review Boards of Seoul National University Hospital (approval no. 1806-089-951), and all procedures were performed after obtaining written informed consent from the participants.

Self-reported questionnaires (subjective sleep parameters) All participants completed self-reported questionnaires to obtain demographic and sleep-related information, as well as medical, psychiatric, neurological, and family histories. The self-reported questionnaires included the Pittsburgh Sleep Quality Index (PSQI), Epworth Sleepiness Scale (ESS), Beck Depression Inventory (BDI), Beck Anxiety Inventory (BAI), Dysfunctional Beliefs and Attitudes about Sleep (DBAS), International Restless Legs Syndrome Study Group Severity Scale (IRLSSG), Morningness-Eveningness Questionnaire (MEQ), and the Berlin Questionnaire (BQ).

The PSQI has a total of 19 items, and scores range from 0 to 21 points; higher scores indicate poorer subjective sleep quality [21]. The ESS is useful for evaluating daytime sleepiness, where significant daytime sleepiness is indicated by scores $\geq 10$ points [22]. The BDI comprises 21 items, and scores range from 0 to 63 points (0-9, not depressed; $10-23$, moderately depressed; $24-63$, severely depressed) [23]. BAI scores range from 0 to 63 points (22-26, anxious; $27-31$, severe anxious; $\geq 32$, extremely anxious) [24]. DBAS-16 scores range from 0 to 160 ; higher scores indicate more dysfunctional beliefs and attitudes toward sleep [25]. The IRLSSG is a standard instrument for measuring the degree of restless legs syndrome scored as follows: $0-10$ points, mild severity; 11-20 points, moderate severity; $21-30$ points, severity; and 31-40 points, highest severity [26]. The MEQ classifications are as follows: definitely morning, 70-86 points; moderately morning, 59-69 points; intermediate, $42-58$ points; moderately eve- ning, 31-41 points; and definitely evening, $16-30$ points [27]. The BQ consists of three categories: category 1 concerns snoring, category 2 daytime sleepiness, and category 3 hypertension. A high risk of sleep apnea is indicated by a positive score in two or three categories [28].

In the morning following the each night of nocturnal polysomnography (nPSG), participants completed a survey on subjective sleep quality and their opinion of the sleepwear. They indicated how long it took to fall asleep [sleep latency (SL)], how long they slept for [total sleep time (TST)] in minutes, and the total number of awakenings. Sleep quality was scored from 1 (very tired and sleepy) to 4 points (refreshed).

In addition, participants indicated how deep their sleep was, how long they slept for, how often they woke, how many dreams they had, and how comfortable their sleep was, on a 7-point Likert scale (1: slept very lightly/slept very little/woke up very often/ did not dream/very uncomfortable, respectively; 7: slept very deeply/slept for a very long time/did not wake up/had many dreams/very comfortable, respectively). They also scored their overall sleep satisfaction (1 point, very satisfied; 5 points, very dissatisfied) and indicated the reasons for satisfaction/dissatisfaction. The participants also indicated how uncomfortable they were due to the sleepwear, whether they experienced tension and stiffness, the level of discomfort felt in the neck, waist, and back, and the extent of discomfort caused by sleepwear while lying down and moving in bed (i.e., tossing and turning) (1 point, very comfortable; 4 points, very uncomfortable). Finally, they rated the sleepwear in terms of the material, size, tactile sensation, and overall satisfaction (1 point, very satisfied; 5 points, very dissatisfied). The evaluators did not interact with the participants when they were completing the questionnaire.

\section{Polysomnography (objective sleep parameters)}

All participants underwent nPSG for three consecutive nights (adaptation night followed by two nPSG sessions to prevent the first night effect) [29]. The coin flip was used to randomize the order of dressing: when the front side appeared, participants were assigned to wear ES on the second day and CS on the third day; when the back of the coin came out, they were assigned to wear sleepwear in reverse order. They were advised that they could engage in routine activities during the daytime (i.e., outside of the nPSG sessions), but tobacco, alcohol, and caffeine were prohibited for 4 days before the adaptation night. The temperature, humidity, and lighting conditions of the sleep laboratory were kept constant.

ProFusion EEG software (ver. 3.4; Compumedics Ltd., Melbourne, Australia) was used for the nPSG recordings. The electrodes and sensors were attached to the participants in a standard manner. Electroencephalogram, electrooculogram, chin electromyogram, electrocardiogram, snoring sounds, oral and nasal airflow, chest movement, abdominal movement, limb movement, body position, and arterial oxygen saturation were continuously recorded during nighttime sleep. The PSG results 
were scored based on American Academy of Sleep Medicine (AASM) criteria [30]. Sleep architecture and related variables (time in bed, TST, wake after sleep onset, SL, sleep efficiency, the proportions of N1, N2, N3, and REM sleep, and apnea-hypopnea index, the periodic limb movement index) were analyzed.

\section{Types of sleepwear}

The ES and CS were identical so that participants could not identify them (gray short-sleeved tops and long gray pants). The order of wear was randomized. All clothes were supplied by Venex Co., Ltd. (Atsugi, Japan).

\section{Statistical analysis}

Data were analyzed using SPSS software (ver. 25.0; IBM Corp., Armonk, NY, USA). The paired t-test was performed to compare objective and subjective sleep parameters between the CS and ES. Any effect of adaptation was evaluated by comparing the data between the second and third nights. Groups distinguished based on a PSQI cutoff score of 5 were also compared, to explore whether the results differed according to subjective sleep quality. A p-value $<0.05$ was considered significant.

\section{RESULTS}

\section{Demographic and baseline clinical characteristics}

The demographic and baseline characteristics of all participants are summarized in Table 1. Table 2 shows the mean and standard deviation of objective and subjective sleep parameters for all participants, seven of whom wore the ES first and then the CS; the other seven wore the two types of sleepwear the reverse order.

\section{Comparison of objective sleep parameters between the} experimental and control sleepwear

The objective sleep variables did not differ significantly between the two sleepwear (Table 2). We divided groups using PSQI and performed the same analysis in order to see if these results differed according to the quality of sleep. Among participants with a PSQI score $<5$ who reported relatively high sleep quality, a tendency toward a longer TST was observed when wearing the ES compared to the CS (ES, 447.44 $\pm 37.31 \mathrm{~min}$; CS, $433.61 \pm 28.39 \mathrm{~min} ; \mathrm{p}=0.06$ ) (Table 3 ). An analysis of the five participants who reported relatively poor sleep quality (PSQI $\geq 5$ ) showed no significant differences in any parameter between the ES and CS.

Comparison of subjective sleep parameters between the experimental and control sleepwear

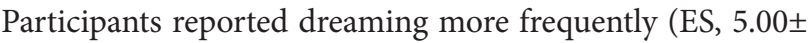
1.84; CS, 3.39 $\pm 1.42 ; \mathrm{p}=0.03$ ), and less discomfort due to tossing and turning (ES, $3.43 \pm 0.76$; CS, 3.71 $\pm 0.47 ; \mathrm{p}=0.04$ ) when wearing the ES compared to the CS. No difference was seen in any other variable by sleepwear (Table 2).
Table 1. Demographic and baseline clinical characteristics of the participants

\begin{tabular}{|c|c|}
\hline Variables & All $(n=14)$ \\
\hline \multicolumn{2}{|l|}{ Demographic } \\
\hline Age (yr) & $29.43 \pm 8.58$ \\
\hline Sex (M:F) & $5: 9$ \\
\hline \multicolumn{2}{|l|}{ Self-reported questionnaire } \\
\hline PSQI & $4.43 \pm 2.95$ \\
\hline ESS & $7.00 \pm 3.40$ \\
\hline BDI & $4.71 \pm 4.12$ \\
\hline BAI & $4.57 \pm 3.69$ \\
\hline DBAS & $117.43 \pm 45.50$ \\
\hline IRLSSG & $0.54 \pm 1.94$ \\
\hline MEQ & $31.29 \pm 3.81$ \\
\hline
\end{tabular}

Data are presented as mean \pm standard deviation. PSQI: Pittsburgh Sleep Quality Index, ESS: Epworth Sleepiness Scale, BDI: Beck Depression Inventory, BAI: Beck Anxiety Inventory, DBAS: Dysfunctional Beliefs and Attitudes about Sleep, IRLSSG: International Restless Legs Syndrome Study Group Severity Scale, MEQ: Morningness-Eveningness Questionnaire

The nine participants with a PSQI $<5$ had more dreams when wearing the $\mathrm{ES}$ compared to the CS (ES, $5.39 \pm 1.52$; CS, 3.50 \pm 1.52 ; $\mathrm{p}=0.01$ ) (Table 3). Among the five participants with a PSQI $\geq 5$, no significant difference in any factor was seen by sleepwear.

Comparison of sleep parameters between the second and third night

Regardless of the type of sleepwear, N2 (\%) stage sleep increased significantly on the third night (second night, $49.18 \pm 8.91 \%$; third night, $56.13 \pm 7.93 \%$; $\mathrm{p}=0.01$ ), while for $\mathrm{N} 3$ (\%) the opposite pattern was seen (second night, $16.60 \pm 3.97 \%$; third night, $10.68 \pm$ $5.10 \%$; $\mathrm{p}<0.001$ ). Participants reported to sleep more comfortably during the third night than the second night (second night, $3.82 \pm 1.54$; third night, $4.61 \pm 1.11 ; \mathrm{p}=0.02$ ).

\section{DISCUSSION}

In this study, we examined whether sleepwear affected sleep parameters (nPSG and self-reported questionnaire measures). None of the objective sleep variables were significantly different between the two types of sleepwear. However, nine participants who reported relatively high sleep quality (PSQI $<5$ ) showed a tendency toward increased TST when wearing the ES compared to the CS. This might be explained by the ES providing a more comfortable and relaxing sleep environment. These results suggested that the ES would be more effective for individuals among the general population who sleep relatively well. A more structured study design and larger number of samples will be needed to verify the effects of the DPV576 sleepwear on objective sleep quality.

N3 (\%) stage sleep tended to increase when wearing the ES, but the difference was not significant. An increase of N3 (\%) indicates deeper sleep, i.e., better sleep quality. Similar to this study, Shin et al. [9] reported that N3 (\%) increased, while N2 (\%) decreased, at a relatively low temperature when wearing wool sleepwear com- 
pared to cotton sleepwear, indicating improved sleep quality. Future studies aiming to replicate our results should include more participants; the lack of significant differences in objective sleep variables in our study may have been due to the small sample size.

When wearing the ES, participants reported significantly more dreams than the CS. We were unable to determine the reason for this finding. Participants with the ES also reported less discomfort due to tossing and turning than those with the CS. Even considering the ceiling effect seen for the questionnaire scores, it seems that the ES was more comfortable than the CS during movement.
Although the mechanism of effect of the ES on sleep parameters is not clear yet, prior researchers assumed that DPV576 functional sleepwear seems to be benefit through the following results. According to a study, DPV576 might contribute to activate keratinocytes via multiple signal pathways, such as TRPV4 receptors which are one of the transient receptor potential channels and associated with inflammation and pain, while reducing stress $[16,19]$. It was also demonstrated that DPV576 functional sleepwear were able to increase infra-red absorption and regulate temperature, which was associated with better sleep quality [31]. More research should be conducted on the mechanism by which

Table 2. Polysomnographic and subjective sleep variables of all participants: comparison between ES and CS $(n=14)$

\begin{tabular}{|c|c|c|c|c|c|}
\hline Variables & ES & CS & Differences & $95 \% \mathrm{CI}$ & p-value \\
\hline \multicolumn{6}{|l|}{ Polysomnography } \\
\hline TRT (min) & $467.96 \pm 33.61$ & $455.46 \pm 27.90$ & $12.50 \pm 37.19$ & $-8.98-33.98$ & 0.23 \\
\hline TST (min) & $432.21 \pm 46.46$ & $425.50 \pm 38.34$ & $6.71 \pm 37.42$ & $-14.89-28.32$ & 0.51 \\
\hline SE (\%) & $92.41 \pm 7.48$ & $93.34 \pm 3.90$ & $-0.93 \pm 5.16$ & $-3.91-2.05$ & 0.51 \\
\hline WASO (min) & $23.68 \pm 30.50$ & $17.50 \pm 12.10$ & $6.18 \pm 22.28$ & $-6.69-19.04$ & 0.32 \\
\hline $\mathrm{SL}(\min )$ & $11.36 \pm 11.79$ & $11.11 \pm 8.30$ & $0.25 \pm 10.88$ & $-6.03-6.53$ & 0.93 \\
\hline$\%$ stage $\mathrm{N} 1$ & $9.63 \pm 5.02$ & $9.73 \pm 6.23$ & $-0.10 \pm 4.77$ & $-2.86-2.66$ & 0.94 \\
\hline$\%$ stage $\mathrm{N} 2$ & $52.56 \pm 8.15$ & $52.31 \pm 10.09$ & $0.24 \pm 11.45$ & $-6.37-6.85$ & 0.94 \\
\hline$\%$ stage $\mathrm{N} 3$ & $14.51 \pm 5.82$ & $12.76 \pm 5.02$ & $1.75 \pm 8.49$ & $-3.15-6.65$ & 0.45 \\
\hline \% stage REM & $23.29 \pm 4.13$ & $25.19 \pm 4.71$ & $-1.91 \pm 4.01$ & $-4.22-0.41$ & 0.10 \\
\hline $\mathrm{AHI}(/ \mathrm{h})$ & $3.40 \pm 6.31$ & $3.79 \pm 5.53$ & $-0.39 \pm 1.82$ & $-1.44-0.67$ & 0.44 \\
\hline Average $\mathrm{O}_{2}(\%)$ & $96.36 \pm 0.93$ & $96.29 \pm 0.99$ & $0.07 \pm 0.83$ & $-0.41-0.55$ & 0.75 \\
\hline Minimum $\mathrm{O}_{2}(\%)$ & $91.29 \pm 3.71$ & $90.86 \pm 4.09$ & $0.43 \pm 3.01$ & $-1.31-2.16$ & 0.60 \\
\hline PLMSI (/h) & $0.61 \pm 2.05$ & $2.82 \pm 5.87$ & $-2.21 \pm 5.36$ & $-5.30-0.89$ & 0.15 \\
\hline \multicolumn{6}{|l|}{ Self-reported questionnaire } \\
\hline $\mathrm{SL}(\min )$ & $22.00 \pm 21.68$ & $20.93 \pm 14.75$ & $1.07 \pm 21.85$ & $-11.55-13.69$ & 0.86 \\
\hline TST (min) & $437.86 \pm 52.50$ & $426.43 \pm 47.49$ & $11.43 \pm 47.37$ & $-15.92-38.78$ & 0.38 \\
\hline Number of awakenings & $3.50 \pm 1.64$ & $3.14 \pm 2.21$ & $0.36 \pm 2.03$ & $-0.82-1.53$ & 0.52 \\
\hline Score on feeling refreshed after sleep & $2.79 \pm 0.97$ & $2.86 \pm 0.86$ & $-0.07 \pm 1.07$ & $-0.69-0.55$ & 0.81 \\
\hline \multicolumn{6}{|l|}{ Scores on sleep quality } \\
\hline Deep sleep & $4.21 \pm 1.83$ & $4.82 \pm 1.41$ & $-0.61 \pm 1.78$ & $-1.63-0.42$ & 0.22 \\
\hline Amount of sleep & $4.57 \pm 1.28$ & $4.79 \pm 1.05$ & $-0.21 \pm 1.12$ & $-0.86-0.43$ & 0.49 \\
\hline FOA & $3.39 \pm 1.44$ & $4.07 \pm 1.33$ & $-0.68 \pm 1.84$ & $-1.74-0.38$ & 0.19 \\
\hline FOD & $5.00 \pm 1.84$ & $3.39 \pm 1.42$ & $1.61 \pm 2.40$ & $0.22-2.99$ & $0.03^{*}$ \\
\hline Comfortable & $4.11 \pm 1.18$ & $4.32 \pm 1.59$ & $-0.21 \pm 1.31$ & $-0.97-0.54$ & 0.55 \\
\hline Overall sleep satisfaction & $2.64 \pm 1.15$ & $2.57 \pm 0.94$ & $0.07 \pm 1.00$ & $-0.50-0.65$ & 0.79 \\
\hline \multicolumn{6}{|l|}{ Scores on sleepwear } \\
\hline Comfort & $3.71 \pm 0.61$ & $4.00 \pm 0.00$ & $-0.29 \pm 0.61$ & $-0.64-0.07$ & 0.10 \\
\hline Relax & $3.86 \pm 0.36$ & $4.00 \pm 0.00$ & $-0.14 \pm 0.36$ & $-0.35-0.07$ & 0.16 \\
\hline Comfort in neck & $4.00 \pm 0.00$ & $4.00 \pm 0.00$ & - & - & - \\
\hline Comfort in waist & $4.00 \pm 0.00$ & $3.86 \pm 0.36$ & $0.14 \pm 0.36$ & $-0.07-0.35$ & 0.16 \\
\hline Comfort in back & $3.93 \pm 0.27$ & $4.00 \pm 0.00$ & $-0.07 \pm 0.27$ & $-0.23-0.08$ & 0.34 \\
\hline Tossing and turning & $3.43 \pm 0.76$ & $3.71 \pm 0.47$ & $-0.29 \pm 0.47$ & -0.56 to -0.02 & $0.04^{*}$ \\
\hline Satisfaction with material & $1.79 \pm 0.97$ & $1.64 \pm 0.74$ & $0.14 \pm 0.86$ & $-0.36-0.64$ & 0.55 \\
\hline Satisfaction with size & $2.14 \pm 0.86$ & $2.07 \pm 1.00$ & $0.07 \pm 0.62$ & $-0.28-0.43$ & 0.67 \\
\hline Satisfaction with tactile sensation & $1.79 \pm 0.89$ & $1.50 \pm 0.65$ & $0.29 \pm 0.83$ & $-0.19-0.76$ & 0.22 \\
\hline Overall satisfaction & $1.93 \pm 0.83$ & $1.86 \pm 0.66$ & $0.07 \pm 0.73$ & $-0.35-0.49$ & 0.72 \\
\hline
\end{tabular}

${ }^{*} \mathrm{p}<0.05$. Data are presented as mean \pm standard deviation. ES: experimental sleepwear, CS: control sleepwear, TRT: total recording time, TST: total sleep time, SE: sleep efficiency, WASO: wake after sleep onset time, SL: sleep latency, REM: rapid eye movement, AHI: apnea-hypopnea index, PLMI: periodic limb movement index, FOA: frequency of awakenings, FOD: frequency of dreams, CI: confidence interval 
DPV576 acts on the body and shows beneficial effects.

N2 (\%) increased, and N3 (\%) decreased significantly, during the third night compared to the second night. However, it was difficult to analyze the relative proportions of the sleep stages based on only 2 nights of nPSG data. Moreover, the results differed between the subjective and objective measures. The more comfortable sleep reported during the third versus second night indicates that participants gradually adapted to the test environment during the experiment. Future studies should validate these results in the same experimental environment.

Some limitations of this study should be discussed. First, the statistical power may have been limited by the small sample size. Second, only healthy adults who slept relatively well participated in this study. Third, there was only one night of nPSG each while wearing the ES and CS, which is insufficient to fully understand the trends in the results. Therefore, future studies should include larger samples, more than two nights of nPSG with each type of sleepwear, and insomnia patients (for generalizability of the effects of sleepwear).

Despite these limitations, this study was significant in that it assessed sleep quality while wearing two different types of sleepwear, based on both objective and subjective measurements. We

Table 3. Polysomnographic and subjective sleep variables of participants with low PSQI scores (<5): comparison between ES and CS ( $n=9)$

\begin{tabular}{|c|c|c|c|c|c|}
\hline Variables & ES & $\mathrm{CS}$ & Differences & $95 \% \mathrm{CI}$ & p-value \\
\hline \multicolumn{6}{|l|}{ Polysomnography } \\
\hline TRT (min) & $471.94 \pm 36.84$ & $457.33 \pm 23.49$ & $14.61 \pm 21.21$ & $-1.70-30.92$ & 0.07 \\
\hline TST (min) & $447.44 \pm 37.31$ & $433.61 \pm 28.39$ & $13.83 \pm 19.38$ & $-1.07-28.73$ & 0.06 \\
\hline SE (\%) & $94.86 \pm 3.96$ & $94.86 \pm 2.58$ & $0.00 \pm 3.35$ & $-2.57-2.57$ & 1.00 \\
\hline WASO (min) & $13.22 \pm 13.87$ & $11.94 \pm 8.21$ & $1.28 \pm 11.38$ & $-7.47-10.03$ & 0.74 \\
\hline $\mathrm{SL}(\mathrm{min})$ & $10.67 \pm 12.34$ & $10.33 \pm 9.00$ & $0.33 \pm 10.98$ & $-8.10-8.77$ & 0.93 \\
\hline$\%$ stage N1 & $8.22 \pm 3.93$ & $7.34 \pm 3.15$ & $0.88 \pm 2.18$ & $-0.80-2.55$ & 0.26 \\
\hline$\%$ stage N2 & $54.41 \pm 7.17$ & $53.13 \pm 9.88$ & $1.28 \pm 10.11$ & $-6.50-9.05$ & 0.71 \\
\hline$\%$ stage N3 & $13.32 \pm 6.21$ & $13.21 \pm 4.73$ & $0.11 \pm 7.42$ & $-5.59-5.81$ & 0.97 \\
\hline \% stage REM & $24.02 \pm 4.70$ & $26.31 \pm 5.15$ & $-2.29 \pm 3.50$ & $-4.98-0.40$ & 0.09 \\
\hline $\mathrm{AHI}(/ \mathrm{h})$ & $0.96 \pm 1.23$ & $1.73 \pm 2.08$ & $-0.78 \pm 1.47$ & $-1.90-0.35$ & 0.15 \\
\hline Average $\mathrm{O}_{2}(\%)$ & $96.67 \pm 0.71$ & $96.44 \pm 0.73$ & $0.22 \pm 0.97$ & $-0.52-0.97$ & 0.51 \\
\hline Minimum $\mathrm{O}_{2}(\%)$ & $93.00 \pm 2.18$ & $92.89 \pm 2.20$ & $0.11 \pm 3.33$ & $-2.45-2.67$ & 0.92 \\
\hline PLMSI (/h) & $0.10 \pm 0.30$ & $2.78 \pm 6.60$ & $-2.68 \pm 6.65$ & $-7.79-2.43$ & 0.26 \\
\hline \multicolumn{6}{|l|}{ Self-reported questionnaire } \\
\hline SL (min) & $17.22 \pm 9.39$ & $17.78 \pm 10.03$ & $-0.56 \pm 14.24$ & $-11.50-10.39$ & 0.91 \\
\hline TST (min) & $447.78 \pm 38.33$ & $426.67 \pm 47.17$ & $21.11 \pm 31.80$ & $-3.33-45.55$ & 0.08 \\
\hline Number of awakenings & $3.44 \pm 1.72$ & $3.11 \pm 2.76$ & $0.33 \pm 2.14$ & $-1.31-1.98$ & 0.65 \\
\hline Score on feeling refreshed after sleep & $2.78 \pm 0.97$ & $2.78 \pm 0.97$ & $0.00 \pm 1.00$ & $-0.77-0.77$ & 1.00 \\
\hline \multicolumn{6}{|l|}{ Scores on sleep quality } \\
\hline Deep sleep & $4.06 \pm 1.72$ & $4.72 \pm 1.23$ & $-0.67 \pm 2.00$ & $-2.20-0.87$ & 0.35 \\
\hline Amount of sleep & $4.28 \pm 0.87$ & $4.39 \pm 0.82$ & $-0.11 \pm 0.93$ & $-0.82-0.60$ & 0.73 \\
\hline FOA & $2.94 \pm 1.31$ & $3.83 \pm 1.48$ & $-0.89 \pm 2.03$ & $-2.45-0.67$ & 0.22 \\
\hline FOD & $5.39 \pm 1.52$ & $3.50 \pm 1.52$ & $1.89 \pm 1.76$ & $0.53-3.24$ & $0.01^{*}$ \\
\hline Comfortable & $4.17 \pm 1.09$ & $4.28 \pm 1.46$ & $-0.11 \pm 1.05$ & $-0.92-0.70$ & 0.76 \\
\hline Overall sleep satisfaction & $2.78 \pm 1.2$ & $2.67 \pm 0.87$ & $0.11 \pm 0.93$ & $-0.60-0.82$ & 0.73 \\
\hline \multicolumn{6}{|l|}{ Scores on sleepwear } \\
\hline Comfort & $3.78 \pm 0.67$ & $4.00 \pm 0.00$ & $-0.22 \pm 0.67$ & $-0.73-0.29$ & 0.35 \\
\hline Relax & $3.89 \pm 0.33$ & $4.00 \pm 0.00$ & $-0.11 \pm 0.33$ & $-0.37-0.15$ & 0.35 \\
\hline Comfort in neck & $4.00 \pm 0.00$ & $4.00 \pm 0.00$ & - & - & - \\
\hline Comfort in waist & $4.00 \pm 0.00$ & $3.78 \pm 0.44$ & $0.22 \pm 0.44$ & $-0.12-0.56$ & 0.17 \\
\hline Comfort in back & $4.00 \pm 0.00$ & $4.00 \pm 0.00$ & - & - & - \\
\hline Tossing and turning & $3.44 \pm 0.73$ & $3.78 \pm 0.44$ & $-0.33 \pm 0.50$ & $-0.72-0.05$ & 0.08 \\
\hline Satisfaction with material & $1.78 \pm 0.97$ & $1.78 \pm 0.83$ & $0.00 \pm 0.71$ & $-0.54-0.54$ & 1.00 \\
\hline Satisfaction with size & $2.00 \pm 1.00$ & $2.00 \pm 1.22$ & $0.00 \pm 0.50$ & $-0.38-0.38$ & 1.00 \\
\hline Satisfaction with tactile sensation & $1.89 \pm 0.93$ & $1.56 \pm 0.73$ & $0.33 \pm 0.87$ & $-0.33-1.00$ & 0.28 \\
\hline Overall satisfaction & $2.00 \pm 0.87$ & $2.00 \pm 0.71$ & $0.00 \pm 0.50$ & $-0.38-0.38$ & 1.00 \\
\hline
\end{tabular}

${ }^{*} \mathrm{p}<0.05$. Data are presented mean \pm standard deviation. ES: experimental sleepwear, CS: control sleepwear, TRT: total recording time, TST: total sleep time, SE: sleep efficiency, WASO: wake after sleep onset time, SL: sleep latency, REM: rapid eye movement, AHI: apnea-hypopnea index, PLMI: periodic limb movement index, FOA: frequency of awakenings, FOD: frequency of dreams, CI: confidence interval 
demonstrated the importance of the sleep environment, including the effect of DPV576 functional sleepwear, especially to subjective sleep quality. The results suggested that objective and subjective sleep parameters vary depending on the type of sleepwear.

\section{Acknowledgments}

This research was supported by Venex Co., Ltd.

\section{Conflicts of Interest}

The authors have no potential conflicts of interest to disclose.

\section{Author Contributions}

Conceptualization: Yu Jin Lee. Data curation: Ha Young Lee, Mi hyun Lee. Formal analysis: Ha Young Lee. Funding acquisition: Yu Jin Lee. Investigation: Ha Young Lee, Jeong Eun Jeon. Methodology: Yu Jin Lee. Supervision: Kyung Hwa Lee, Yu Jin Lee. Writing-original draft: Ha Young Lee. Writing-review \& editing: Ha Young Lee, Mi hyun Lee, Yu Jin Lee.

\section{ORCID iDs}

Yu Jin Lee (1)

https://orcid.org/0000-0001-5195-2579

Ha Young Lee (1)

https://orcid.org/0000-0002-7769-400X

\section{REFERENCES}

1. Hirshkowitz M, Whiton K, Albert SM, Alessi C, Bruni O, DonCarlos L, et al. National Sleep Foundation's sleep time duration recommendations: methodology and results summary. Sleep Health 2015;1:40-43.

2. Troynikov O, Watson CG, Nawaz N. Sleep environments and sleep physiology: a review. J Therm Biol 2018;78:192-203.

3. Amrit UR. Bedding textiles and their influence on thermal comfort and sleep. AUTEX Res J 2007;8:252-254.

4. Kayaba M, Ogata H, Park I, Ishihara A, Kawana F, Kokubo T, et al. Improvement of slow wave sleep continuity by mattress with better body pressure dispersal. Sleep Med Res 2019;10:75-82.

5. Choi JW, Lee Yu, Kim S, Lee J, Jeong DU. Comparative effects of mattress type on subjective and objective sleep quality: a preliminary study. Sleep Med Psychophysiol 2016;23:61-67.

6. Lan L, Lian Z. Ten questions concerning thermal environment and sleep quality. Build Environ 2016;99:252-259.

7. Jeong JR, Kim HE. Effects of skin pressure by all-in-one on the rhythm of body temperature during sleep. Fashion Text Res J 2010;12:830-836.

8. Chow CM, Shin M, Mahar TJ, Halaki M, Ireland A. The impact of sleepwear fiber type on sleep quality under warm ambient conditions. Nat Sci Sleep 2019;11:167-178.

9. Shin M, Halaki M, Swan P, Ireland AH, Chow CM. The effects of fabric for sleepwear and bedding on sleep at ambient temperatures of $17^{\circ} \mathrm{C}$ and $22^{\circ} \mathrm{C}$. Nat Sci Sleep 2016;8:121-131.

10. Glovinsky P, Zavrel E. Sleepwear with lateralized thermal properties for the treatment of sleep disturbance in women. Int J Cloth Sci Tech 2018;30:6272.

11. Ghoneum M, Ghoneum A, Tolentino L, Gimzewski J. Modulation of aged murine T lymphocytes in vivo by DPV576-C, a nanodiamond- and nanoplatinum-coated material. In Vivo 2010;24:141-146.

12. Ghoneum MH, Gimzewski JK, Ghoneum A, Katano H, Paw U CN, Agrawal A. Inhibition of TRPV1 channel activity in human $\mathrm{CD} 4^{+} \mathrm{T}$ cells by nanodiamond and nanoplatinum liquid, DPV576. Nanomaterials (Basel) 2018;8:770.

13. Ghoneum A, Zhu H, Woo J, Zabinyakov N, Sharma S, Gimzewski JK. Biophysical and morphological effects of nanodiamond/nanoplatinum solution (DPV576) on metastatic murine breast cancer cells in vitro. Nanotechnology 2014;25:465101.

14. Ghoneum A, Sharma S, Gimzewski J. Nano-hole induction by nanodiamond and nanoplatinum liquid, DPV576, reverses multidrug resistance in human myeloid leukemia (HL60/AR). Int J Nanomedicine 2013;8:2567-2573.

15. Ghoneum M, Ghoneum A, Gimzewski J. Nanodiamond and nanoplatinum liquid, DPV576, activates human monocyte-derived dendritic cells in vitro. Anticancer Res 2010;30:4075-4079.

16. Choi Y, Makita M, Nakamura Y, Yamamoto K, Nara T, Kawamura T, et al. Effect of novel recovery garments utilising nanodiamond- and nanoplatinum-coated materials (DPV576-C) on physical and psychological stress in baseball players: a randomised, placebo-controlled trial. Eur J Sport Sci 2019;19:869-875.

17. Zinke F, Bakenecker P, Hahn D. Influence of platinum harmonized textile on neuromuscular, systemic and subjective recovery. PLoS One 2017;12: e0186162.

18. Zinke F, Bakenecker P, Hahn D. Correction: influence of platinum harmonized textile on neuromuscular, systemic and subjective recovery. PLoS One 2018;13:e0191057.

19. Ghoneum MH, Katano H, Agrawal S, Ganguly S, Agrawal A. Effect of nanodiamond and nanoplatinum liquid, DPV576, on human primary keratinocytes. J Biomed Nanotechnol 2017;13:110-116.

20. American Psychiatric Association. Diagnostic and statistical manual of mental disorders (DSM-5 ${ }^{\circledR}$ ). Washington, DC: American Psychiatric Pub; 2013.

21. Buysse DJ, Reynolds CF 3rd, Monk TH, Berman SR, Kupfer DJ. The Pittsburgh Sleep Quality Index: a new instrument for psychiatric practice and research. Psychiatry Res 1989;28:193-213.

22. Cho YW, Lee JH, Son HK, Lee SH, Shin C, Johns MW. The reliability and validity of the Korean version of the Epworth sleepiness scale. Sleep Breath 2011;15:377-384.

23. Hahn HM. A standardization study of Beck Depression Inventory in Korea. J Korean Neuropsychiatr Assoc 1982;25:487-502.

24. Kwon SM. Assessment of psychopathology in anxiety disorder. Korean J Psychopathol 1997;6:37-51.

25. Morin CM, Vallières A, Ivers $H$. Dysfunctional beliefs and attitudes about sleep (DBAS): validation of a brief version (DBAS-16). Sleep 2007;30: 1547-1554.

26. Wunderlich GR, Evans KR, Sills T, Pollentier S, Reess J, Allen RP, et al; International Restless Legs Syndrome Study Group. An item response analysis of the international restless legs syndrome study group rating scale for restless legs syndrome. Sleep Med 2005;6:131-139.

27. Yu NJ, Shin SC, Wang SK. A study on the standardization of the Korean version of JA Horne and O. Ostbergs' Morningness-Eveningness Questionnaire and on the sleep pattern. J Korean Neuropsychiatr Assoc 1995;34:642-656.

28. Kang HH, Kang JY, Lee SH, Moon HS. The usefulness of the Berlin Questionnaire as a screening for obstructive sleep apnea in a sleep clinic population. Sleep Med Psychophysiol 2011;18:82-86.

29. Mendels J, Hawkins DR. Sleep laboratory adaptation in normal subjects and depressed patients ("first night effect"). Electroencephalogr Clin Neurophysiol 1967;22:556-558.

30. Iber C, Ancoli-Israel S, Chesson AL, Quan SF. The AASM manual for the scoring of sleep and associated events: rules, terminology, and technical specifications. Westchester, IL: American Academy of Sleep Medicine; 2007.

31. Fujimura T, Nakamura T, Shiozaki S, inventors; Venex Co., Ltd (Kanagawa, JP), Vision Development Co., Ltd (Tokyo, JP), assigness. Fibers comprising nanodiamond and platinum nanocolloid, and bedding formed thereby. United States patent US 9005751. 2015 Apr 14. 